\title{
Second-Language Learners from Collectivistic Societies own Self-Efficacy Effects on Performance and Self Perception of Career Success.
}

Carlos Parra, Ph.D

La Sierra University, California, USA

Nanci Geriguis-Mina

La Sierra University, California, USA

\section{Abstract}

In reference to cultural patterns in collectivistic societies, teaching and learning are greatly influenced by the teachers' collectivistic or individualistic cultural orientation (Kaur \& Noman, 2015). However, in dealing with both audiences and their teaching platforms, a chasm appears between methodologies and their applications since collectivistic societies are reluctant to accept methodologies perceived as mere Western innovations. In other words, a seemingly pedagogical incongruence arises where direct individualistic Western influence is perceived as unsuitable to a collectivistic mindset. One must keep in mind that family members in collectivist societies, who view themselves as part of a group rather than independent individuals, seem to feel more interdependent and mutually responsible for each other.

In addition to Vygotski's assertion that children's cognitive development is enriched through social interaction with more skilled individuals (1978), Bandura (1982) emphasizes that the degree to which learners believe in their own self-efficacy influences their functioning cognitively, motivationally, emotionally, and their decision making process. Also, self-efficacy is perceived to accelerate the process of adapting to a new environment while learners adopt new cultural practices and consent to norms and expectations. In our exploration, second-language learners (SLLs) from collectivistic societies advance academically-English as a second language included-within the frame of sociocultural theory, since they seem to be motivated by their culturallyinduced sense of obligation to honor their parents and other group members. These SLLs are positively influenced by their prior experiences with the group's perceptions and expectations of their capability to learn an additional language (Bandura \& Schunk, 1981; Schunk, 1991). Our research seems to indicate that this outcome is significantly affected by the self-efficacy and self-reliance produced by prior successes in challenging tasks that may have been mandated by the SLL's elders. In addition, SLLs also seem to succeed in accomplishing more challenging goals as they observe their families' values and traditions even when they are in a society that enforces individualistic values.

Keywords: second-language learners; collectivistic societies; self-efficacy; self-perception; language acquisition; career success; performance. 


\section{Introduction}

In the exploration for more effective methods for language acquisition, much has been debated and unveiled in reference to how humans acquire, maintain, and refine a new language, such as English, while in a new and unfamiliar environment. Pursuing this endeavor, we are cognizant of the fact that learning takes place, and is reaffirmed, through social events when referring to Second Language Acquisition (SLA) and from the perspective of the sociocultural theory (SCT) (Cook, 2008). For over half a century, we have been aware that learning occurs through stimuli and responses made into habits through simple reinforcements (Skinner, 1957). In addition, there are direct implications on SLL's language acquisition when applying SCT's cognitive and social perspectives (Aimin, 2013) in which human learning takes place through continued cognitive, behavioral, and environmental interactions (Vygotsky, 1978; Lantolf \& Thome, 2006). Also, from an SCT perspective, SLA is altered by the complexities of the environment in which the SLL is in (Vygotski, 1978). Furthermore, SCT distinguishes itself from other cognitive theories by suggesting that higher forms of mental activity and the internal system of meaning are developed through self-mediated social interaction by symbolic means, and through the environment (Vygotski, 1987).

In reference to cultural patterns in collectivistic societies, teaching and learning are greatly influenced by the teachers' collectivistic or individualistic cultural orientation (Kaur \& Noman, 2015). However, in dealing with both audiences and their teaching platforms, a chasm appears between methodologies and their applications since collectivistic societies seem to be reluctant to accept methodologies perceived as mere Western innovations. In other words, a seemingly pedagogical incongruence arises where direct individualistic Western influence is perceived as unsuitable to a collectivistic mindset. One must keep in mind that family members in collectivist societies, who view themselves as part of a group rather than independent individuals, seem to feel more interdependent and mutually responsible for each other.

\section{Perception of Self-Efficacy}

In addition to Vygotski's assertion that children's cognitive development is enriched through social interaction with more skilled individuals (1978), Bandura's (1977) social persuasion theory asserts that having a knowledgeable and ethical mentor can significantly influence the person's self-efficacy by providing mastery experiences. Also, Bandura (1982) emphasizes that the degree to which learners believe in their own self-efficacy influences the way in which they function cognitively, motivationally, and emotionally, and affects their decision making process. Clearly, self-efficacy is perceived to accelerate the process of adapting to a new environment while learners adopt new cultural practices and consent to norms and expectations. It has also been expressed by SCT, self-efficacy mechanisms play a central role in personal empowerment and 
accurate appraisal of self (Bandura, 1982; 1986). In our exploration, SLLs from collectivistic societies advance academically-English as a second language included-within the frame of SCT, since they seem to be motivated by their culturally-induced sense of obligation to honor their parents and other group members. These SLLs are positively influenced by their prior experiences with the group's perceptions and expectations of their capability to learn an additional language (Bandura \& Schunk, 1981; Schunk, 1991). Our research seems to indicate that this outcome is significantly affected by the self-efficacy and self-reliance produced by prior successes in challenging tasks that may have been mandated by the SLLs' elders. In addition, SLLs also seem to succeed in accomplishing more challenging goals as they observe their families' values and traditions even when they are in a society that enforces individualistic values.

When referring to SLLs from collectivist societies, it is of importance to note not only the social environment where the SLLs are attempting to pick up another language, but also the social background of their instructors. It is faulty and inaccurate to assume that SLLs in Western societies are effectively enjoying the perceived benefits of being exposed to an individualist approach. Instead, many of those SLLS already in Western locations are being educated on SLA by a host of instructors who possess a sort of "mixed bag" of social, geographical, and ideological backgrounds. Having a good understanding of the cultures of SLLs does not ensure a balanced outcome, since this aspect may be undermined by the specific ideological background of an ESL instructor. While it is true that teaching methodologies tend to be perceived as the great equalizer, "research reveals the problematic nature of pedagogical situations in which the teacher is from one culture and the student is from another" (Nelson, 2000). Currently, such social encounters and individual interactions in the classroom may be more common than expected, and as Nelson expresses, "students experience less satisfaction in school, tend to learn less, and often fail" (Nelson, 2000). As it is suggested, a certain "adjustment" on the part of the instructors is necessary to counter both negative outcomes, even though it seems beneficial to many SLLS when their instructors can also opt to use methods of instruction or patterns of learning that initially benefited them while acquiring their own language proficiency.

\section{Pedagogical Perspectives}

Not only does the instructor's adjustment to cultural exchanges in the classroom seem to be suggested, but so is an adjustment of their perception and understanding of either collectivist or individualistic pedagogical effectiveness. As it was already suggested, "just as students' learning styles differ on the basis of their cultural orientations, teachers' classroom practices may also differ on the basis of their cultural orientation" (Kaur \& Noman, 2015). It follows then, that due to increasing technological transformation, and because of the fading of international boundaries, these differences are increasingly 
tenuous and less significant since after all, teaching practices in East-Asian societies are also incrementally affected by methodological innovation provided, even imposed, by their Western educational developers' parallels. However, it appears that such Western methodological innovation is at odds with classroom implementation in East-Asian societies, and the obvious outcome is a worrisome rising level of conflicting classroom practices. Indeed, the objectives are at odds since the perceived expectation of effective practices in a collectivist culture seems to be that of transforming knowledge in a format that is structured and direct, while individualistic cultures expect student participation in discussion and inquiry. The biased pattern that follows is that students from collectivist cultures are passive learners, while those from individualistic societies are stereotyped as being active learners. Of course, such claims have also been amply disputed (Cheng, 2000; Littlewood, 2001; Xiao, 2005). It seems that such students do participate actively as they try to achieve a common goal (Littlewood, 2001), and the stereotype created by a pernicious biased pattern is dismantled (Sleeter, 2001) as it points to a clear misunderstanding of social interaction in collectivist societies.

\section{Sense of Collectivism}

When referring to perceived expectations on effective practices in both collectivist and individualistic societies, it seems of significant importance to keep in mind the social interaction effect of behavior and intention. Clearly, both notions operate simultaneously in both cultural spectrums, and their mixed expression visibly affect SLLs in either geographical location. If the "goal of life for a person [is] to work for the prosperity and happiness of the family," as it is expressed by Sihna (2014) in reference to a research and report conducted in a collectivist community in India, then, this form of "collectivism becomes primarily family-centric." SLLs from collectivist societies also seem to develop a significant level of self-reliance, a "typical attribute of individualism" according to Sihna, that "is placed in the service of the family's wellbeing and individual's success is believed to reflect the family's success." (Sihna, 2014). As stated, an attribute of individualism is used to compensate for and capitalize on the benefit of the inner and extended group in a collectivistic society such as the one described above. In fact, that level of self-reliance seems to have a significant impact on the SLLs' perception of self-efficacy when, in their experience, a successful outcome is the result of their own performance, whether they are in an individualistic or collectivistic physical location.

Since the SLLs' level of self-reliance shapes their own perception of self-efficacy as they perform daily routines, we may say such a process does affect even their own pattern of decision making. In other words, self-efficacy becomes a familiar and common notion that either supports or denies the degree of adaptability that SLLs may have acquired as they adjust to another society. Bandura assures us that, "self-efficacy is perceived to accelerate the process of adapting to a new environment while learners adopt new 
cultural expectations" (Bandura, 1982). Surely then, as the adaptation process develops, it is of importance to note the greater level of SLLs' sense of comfort as adoption of cultural expectations are also perceived as fulfillment of goals and objectives within any given society. Surely then, as the SLLs' adaptation process develops, so does their sense of comfort, as adoption of cultural expectations is also perceived as fulfillment of goals and objectives within. In addition, SLLs' fulfillment of goals and objectives is also identified as the societal common denominator that affiliates them with their elders and family advisers back home who continue to advise them to reach objectives perceived by the advisers to be essential.

\section{Study Inquiries and Findings}

Professionals from collectivist societies, who have completed higher education and professional training in the United States, were invited to participate by answering the following research questions:

1. Who influenced your decision to pursue the career that you are practicing, and what is your relationship with that person?

2. Is that person who influenced your decision older or younger than you?

3. In your opinion, which professions are most respected and desired in your society or culture?

4. Did your society/culture have any influence on your career choice?

5. Do you identify more with your original home culture or the general Western American culture?

\section{Characteristics of Participants}

This qualitative study used surveys and individual interviews to investigate the educational journeys of professionals from a number of collectivist societies who acquired significant English language fluency after participating as ELLs. Later they were able to complete their higher education in the U.S. We also examined some of the factors that seem to have influenced their learning and professional training. Six female and 19 male participants were selected from collectivist societies, namely Egypt, Iraq, Jordan, Korea, China, Lithuania, and Nicaragua. They also ranged between 30-60 years of age. All of them arrived to the U.S. with no English language proficiency. Since then, they mastered the English language, pursued their academic and career goals, and are currently practicing their professions. It is worthy to mention that the participants' careers, namely medicine, dentistry, engineering, business, and teaching, are socially perceived to be among the most highly esteemed in their cultures. 


\section{Study Participants}

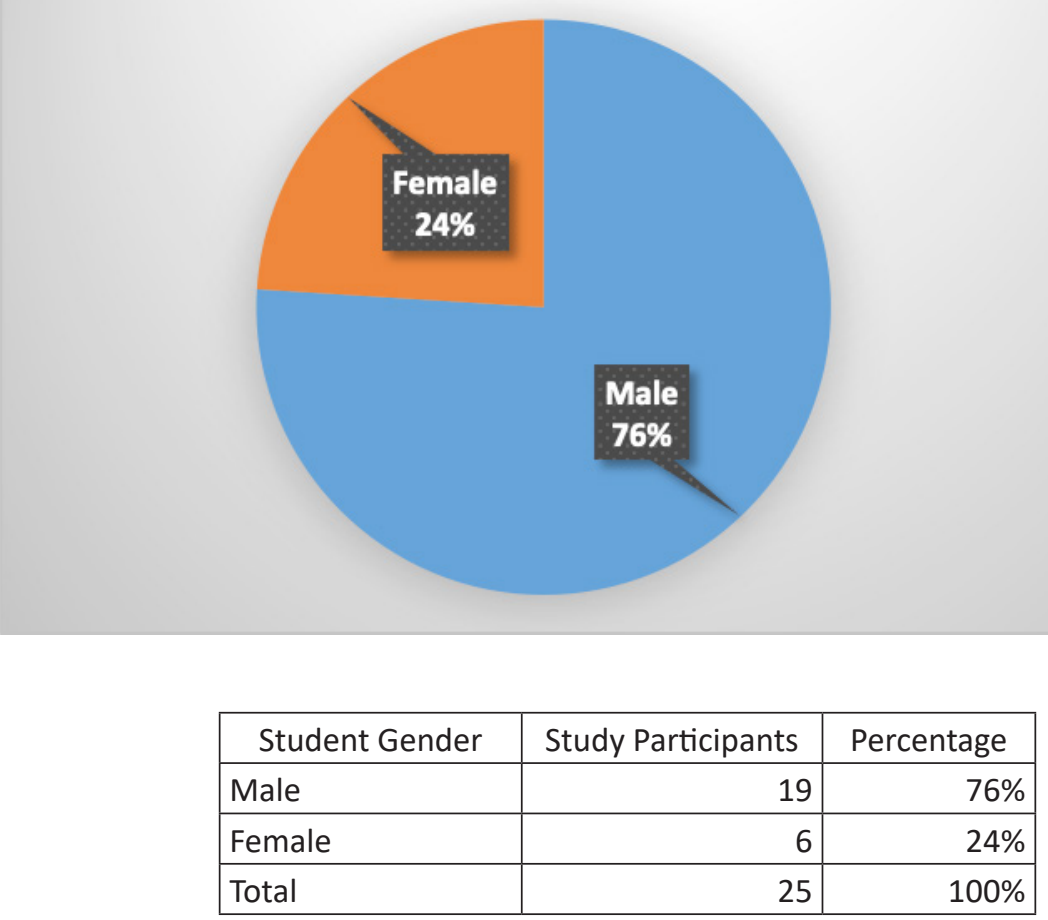

Source: Authors

Participants were invited to engage in this study based on their willingness to share their experiences. Unsolicited, some of them disclosed that their parents may have exerted pressure on them to excel in school and reprimanded them, at times, if and when they presented a low grade, which in many cases was an A-. Approximately $20 \%$ of the participants indicated that their parents pressured them to pursue specific professional careers and groomed them for these careers since their childhood, suggesting that these careers would lead them to financial stability, which translated into happiness. This parental pressure seemed to have prompted them to study harder. At the same time, $76 \%$ of the participants felt that their parents suggested or steered them toward the careers they pursued. Consequently, they earned the expected high grades, which gave them confidence and empowered them to complete challenging tasks. The participants perceived that their parents expected high achievement because they were confident that their children were skilled and could attain these goals. Parents' expectations led the participants to believe in their own abilities and gave them resolve to earn high scores. Their self-efficacy generated confidence in their own abilities to learn the English language upon arriving to the U.S., and later helped them acquire the skills to earn higher learning with the same confidence. 


\section{Felt Pressured by Parents to Pursue Specific Careers}

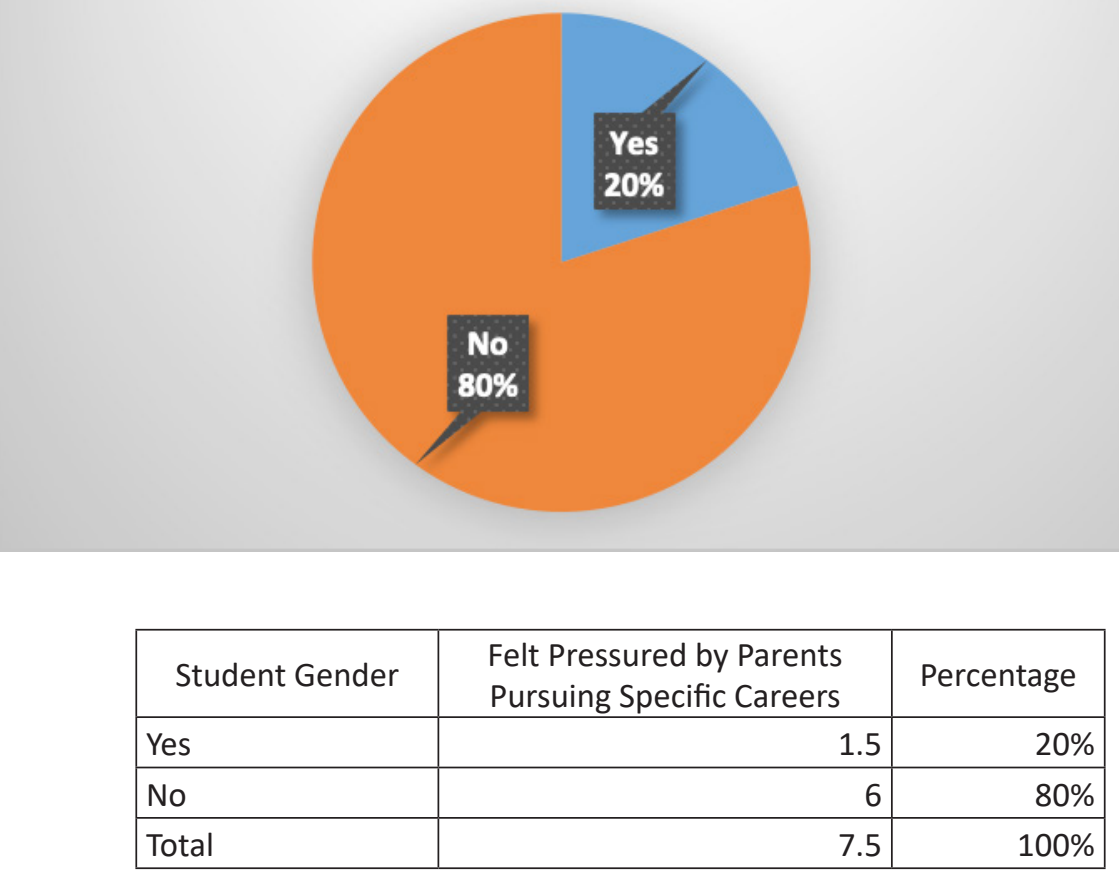

Source: Authors

As a whole, the questionnaire in this study and the conducted interviews revealed and confirmed that family influence and that of their role models had the strongest impact on the participants' career trajectory and professional success. The participants' desire to emulate their role models and honor their families through success motivated them to exert the necessary effort and reach the high standards that were expected of them. Their self-efficacy, which was gained upon achieving previous academic successes in difficult subjects, gave them credence and a strong sense of control over their lives.

\section{Study Findings}

Parents, other family members, older family friends, and teachers had the most influence on career choices and motivated participants to learn English and pursue higher education. Executing their cultural values of respect for their elders and parents and the importance of the family unit, individuals had strong convictions that their future plans did not impact them solely, but affected the entire family, even the community at large. Surveys conducted revealed that a $24 \%$ of the participants chose fields of specialty because either their parents or older group members practice those 
professions, while an additional $64 \%$ were affirmed by parents or group members over the years for being capable to attain goals perceived by the culture to be the loftiest-business, engineering, medicine, dentistry, or pharmacy.

\section{Felt Indirect Suggestions by Parents to Pursue Specific Careers}

\begin{tabular}{|l|r|r|}
\hline & $\begin{array}{c}\text { Felt Indirect Suggestions by Parents } \\
\text { to Pursue Specific Careers }\end{array}$ & Percentage \\
\hline Yes & 19 & $76 \%$ \\
\hline No & 6 & $24 \%$ \\
\hline Total & 25 & $100 \%$ \\
\hline
\end{tabular}

Source: Authors

Consequently, they earned excellent grades in school, as their parents nurtured their efforts and steadily supplied provisions for tutoring. Participants' academic achievements and high test scores, even in subjects generally perceived as difficult, produced self-efficacy that gave them confidence in their capabilities to learn the English language and achieve the careers they, and their parents, aspired for them. Championed by their parents who endorsed earlier scholastic competencies, they were motivated to confidently set high goals for their futures.

\section{High Academic Standards}

All participants indicated that their parents had high expectations of them in every aspect of their lives. Whether both parents worked outside the home or the participants had a stay-at-home mother, $68 \%$ of the participants had private tutors or were enrolled in after-school classes in which they learned more math, languages, and other core 
subjects. The ambitious goals that parents had for their children prompted them to do whatever was necessary to give their offspring the best opportunities to enter into esteemed high-ranking a significant role in students' education, and is regarded as one of the three pillars of education along with school and home (Bray 2009, 1999; Baker et al. 2001).

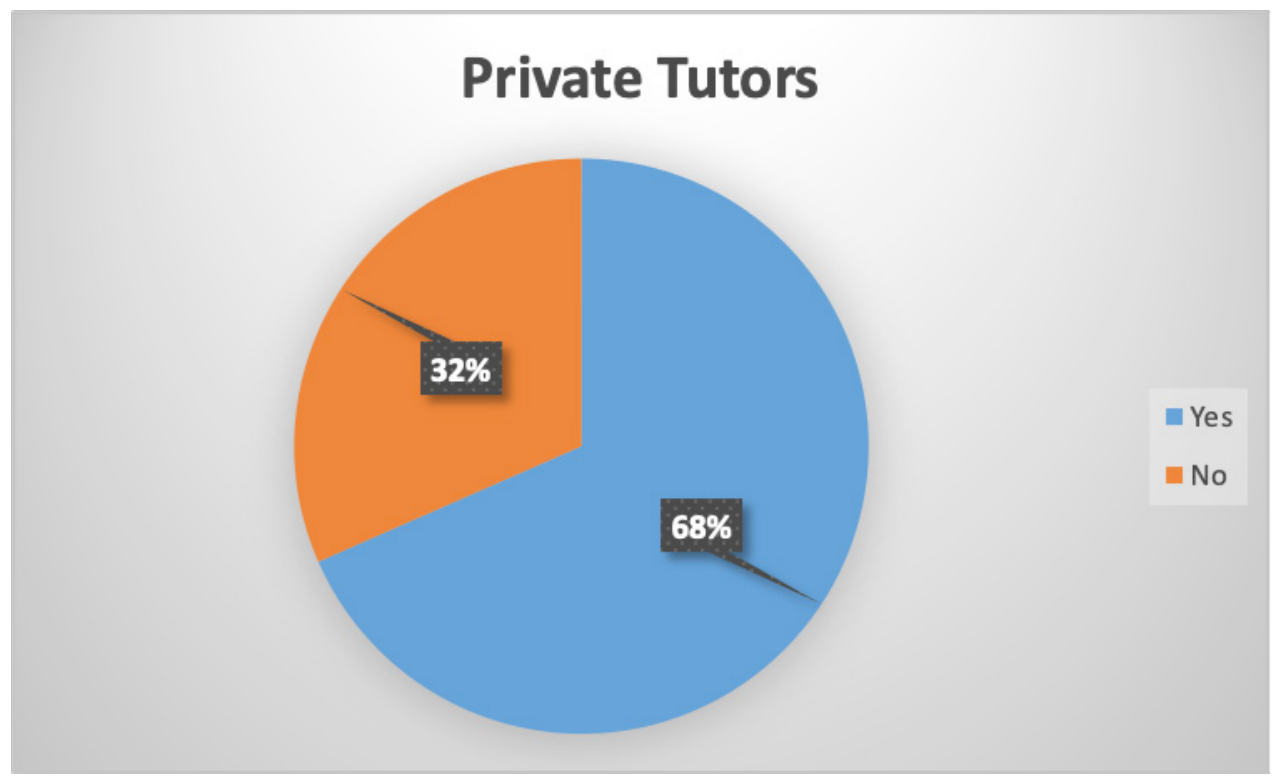

\begin{tabular}{|l|r|r|}
\hline & Private Tutors & Percentage \\
\hline Yes & 13 & $68 \%$ \\
\hline No & 6 & $32 \%$ \\
\hline Total & 19 & $100 \%$ \\
\hline
\end{tabular}

Source: Authors

In an interview conducted with James, a dentist of Korean descent, he expressed that the stringent focus on high achievement began in elementary school when he was in classes from 8:00 o'clock in the morning until 4:00 o'clock in the afternoon, after which he went to a private tutoring academy to study more math and take piano lessons. He remembers that the days were very long and hard, but his parents feared that his grades would fall behind his friends' if they continued to go to the private academy and he didn't, and that his friends would consequently have a higher advantage of getting into high-ranking colleges.

Although academic goals are the primary reason for these high standards, there is also a social status that families strive to maintain, which exerts high pressure on parents and students. Korean fathers, for example, put enormous focus on their children's college admission and academic achievement because they elevate a family's social status (Ahn, 1995). Furthermore, careers in medicine, dentistry, law, engineering, or business 
are highly regarded culturally and socially, and place parents in an advantageous position when children are being compared by groups of parents (Atienza, 2006; Rockwell, 2003; Sue \& Ozazaki, 1990). Moreover, these professions are perceived to allow people to live more financially stable and socially favored lives, which in collectivist cultures, appears to translate into happiness.

In many cases, however, parents propel their children to strive for excellence and aim for perceived successful careers, fueled by the parents' own aspiration and goals for their children's future, rather than by the children's abilities or desires (Seginer, 1983). With Asian parents viewing their children's lives and successes as extensions to theirs, these parents' aspirations are a combination of their appreciation for education, and the esteem that their society places on academic and career success (Astone \& McLanahan, 1991; Carpenter, 2008).

The educational systems in Asian and Middle Eastern countries prompt the parents to take harsh, sometimes punitive, measures toward ensuring their children's academic excellence. Admission into a country's top universities is fiercely competitive, and examination scores in the comprehensive standardized high school exams determine students' majors in college, the educational institution they enroll in, and ultimately, their careers.

James believes that his parents pressed him because they wanted him to earn scores that would qualify him to enter into a high-ranking college to study architectural engineering and eventually dentistry. To achieve these goals, James' parents sent him to a private tutoring academy every day after school where he studied new material until late at night, then he went home to do his homework and study for the next day. The pressure was so intense that James' father used to hit him anytime he earned a "low grade", which by the father's standards was an " $A$-". James admitted, "that made me very sad, very sad. But I was never angry at him because he is my father, and I knew why he did that." But his sense of responsibility to make his father proud motivated him to study harder to earn the grades that his father demanded. "When I found out that I was able to get the perfect grades through hard work and determination, I became confident in my ability to achieve my goals." James promised his father that he was would become a dentist. Through confidence that he developed by reaching challenging academic goals that he set for himself, along with determination and hard work, James became a dentist. "Now I'm thankful that my father set higher standards for me and made me reach them."

\section{Role Models and their Influence on Education}

About $24 \%$ of participants in this study were inspired to pursue higher education and the professional careers practiced by a family member who is a role model and is generally older in age. Participants' admiration for role models, and their own desire to 
emulate them, were influential factors in establishing their career goals and persisting to reach them. Their strong desire to honor their role models-often their parentsby following in their footsteps, led participants to work hard and make the necessary sacrifices to attain their goals, including separating from their families.

Ali, an optometrist of Jordanian descent, articulated his experience by saying,

My oldest cousin studied medicine and became the first physician in our extended family," said Ali, an optometrist who studied English and optometry in the United States. "Everybody in the family was very proud of him, so my older brother followed in his footsteps, and so did another cousin. My oldest cousin was my role model, and I had always admired and respected him, and he encouraged me to consider a career in the medical field. I had observed him since he began to study medicine and after he started his practice, I listened intently as he would share stories about anonymous patients that he treated and made a difference in their lives. He seemed very happy, so I aspired to become like him. I had no doubt that I could accomplish that goal if I studied hard. My brother and cousins were all very instrumental and supportive in my academic journey. Now, seeing the pride in my parents' eyes because I am a doctor makes all the hard work worthwhile.

\section{Inspired by Family Members or Other Role Models}

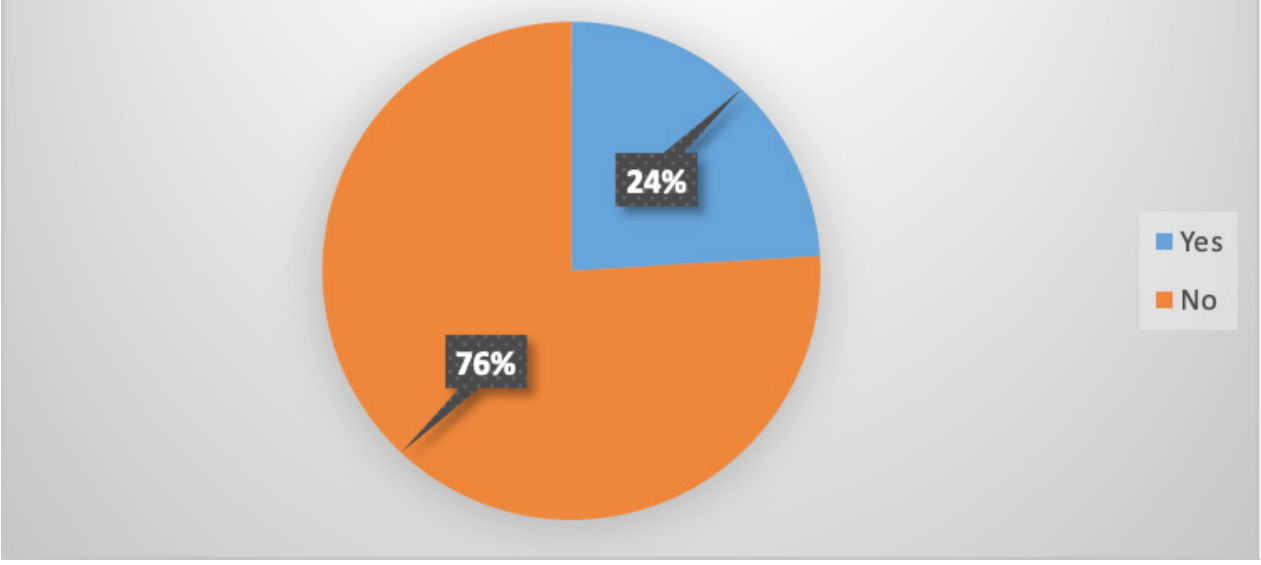

\begin{tabular}{|l|r|r|}
\hline & $\begin{array}{c}\text { Inspired by Family Members or } \\
\text { Other Role Models }\end{array}$ & Percentage \\
\hline Yes & 1.9 & $24 \%$ \\
\hline No & 6 & $76 \%$ \\
\hline Total & 7.9 & $100 \%$ \\
\hline
\end{tabular}

Source: Authors 


\section{High Desire to Honor Parents}

Some Asian cultures are generally guided by Confucian values of love and respect for family. Consequently, offspring in those cultures have the highest respect for and sense of duty toward their parents and aspire to make them proud. A career decision for an individual is a family affair because an individual's success or failure, ultimately reflects on the entire family (Ying et al., 1999). This study revealed that the desire to honor their families or elders and give them a sense of pride influenced the participants' career choices and motivated them to achieve success.

\section{Felt a Sense of Duty to Honor Parents and Make Them Proud by Being Successful Academically and Professionally}

\begin{tabular}{|l|r|r|}
\hline & $\begin{array}{c}\text { Felt a Sense of Duty to Honor Parents and Make Them } \\
\text { Proud by Being Successful Academically and Professionally }\end{array}$ & Percentage \\
\hline Yes & 25 & $100 \%$ \\
\hline No & 0 & $0 \%$ \\
\hline Total & 25 & $100 \%$ \\
\hline
\end{tabular}

Source: Authors

Jacob, a physician of Chinese descent practicing in the U.S., said,

In our culture we live for the family. We appreciate everything they do for us and we have to make them proud. So, if we make our own decision but this decision will make our family upset or disappointed, we just won't act upon it. I frequently think of all the sacrifices that my family made for me. They gave me money, support, time, and everything that I needed, so I have a duty to succeed in life to make them proud. I couldn't live with myself if I let them down. 
Similarly, Steve, a dentist of Korean descent, said,

My mother and father are both dentists and were the best role models for me, and I appreciate and respect them for what they have done for me. In return, I wanted to make them proud and show them how much I appreciated the educational and career opportunities they provided me with. I see how proud they are of me as a dentist, and it is very gratifying for me.

Correspondingly, Matthew, originally from China, understood when he moved to the U.S. to pursue his education that children cannot be separate from their families in the Asian culture. The entire family is one whole unit. He said,

I was raised with the belief that if I didn't do well in school, my family will experience shame. We can't allow that in our culture. In my country, we believe that our lives do not belong to us exclusively. We live for our family and for our social group. We appreciate all that our parents do for us, so we have to make them proud of us, and that responsibility always motivated me.

This study revealed that many Asian cultural values, which are based on Confucianism, remain dominant among Koreans and Chinese individuals who live and practice their careers in the United States. Filial piety, or family honor, is an integral element of the culture and of their families' ideals. Filial piety "defines a hierarchical relationship between generations, particularly that of the parent and the child. In this ordered space, filial piety prescribes the ideology of devotion by the grateful child to the parent, and also places debt and obligation at the heart of the discourse on parentchild relationships.... Using a discourse of gratitude and indebtedness, a hierarchy of power is reproduced in everyday life, privileging the old over the young and the parent over the child" (Ikels, 2004, p. 182).

Moreover, family remains the core reference group for all interactions related to education, finances, or religion (Chao \& Tseng, 1995). Stemming from Confucian teachings, filial piety engenders students' sense of responsibility for their parents' happiness and pride among other family members and social groups, and for preserving the family honor. Some participants disclosed that this sense of duty stunted their capability to make decisions for themselves. Yet, reflecting on Confucius' teachings, they believed that it was not possible to be a good person without showing respect for their parents.

In the Middle East, particularly in Egypt, the family is central to a person's development (Adams, 1957; 1959; Najarian, 1959; Wilber, 1969). Loyalty to one's family influences one's reputation and well-being. Family loyalty is a core value that motivate students to seek academic excellence to prepare for prosperous careers, but perhaps more importantly, to honor their families and make them proud among their friends and relatives. In turn, families are diligently engaged in their members' education, which also contributes to family honor (Sanders, 1986). It is customary for families to hire private 
tutors who go to the family home, often under the supervision of one of the parents, to reinforce learning acquired in school. A substantial portion of an Egyptian family's income is usually dedicated to paying for private tutoring for their children. Families that cannot afford to hire private tutors, gather a group of students, hire one tutor, and divide the fees among the group. Students who do not earn the desired or expected test scores often feel shame, not just for themselves, but for having put their parents through disappointment and embarrassment.

Ramy, an Egyptian engineer who completed his education in the United States, shared that he was influenced by his older brother who was also an engineer. With engineering being among the top three most-esteemed professions in Egyptian society, he aspired to become an engineer from a young age and focused his efforts on classes that would prepare him for that field. Delighted by his goal, his parents furnished all the needed resources to motivate and help him succeed, and offered summer trips as incentives at the end of each school year that concluded with perfect grades. When his standardized high school exam limited him to a business course of study, he was ashamed, particularly that his family had been calling him "The Engineer" all along. Supported by his family, he decided to spend what was slated to be his freshman year in college studying for the high school exam and retake it the following year. Motivated to earn the desired score that would qualify him to enter into a college of engineering, he studied diligently with the help of tutors and his brother, while his entire family refrained from any entertainment or social activities to support and shield him from distractions. When he retook the standardized high school exam, he earned the needed score, and after completing some of his engineering training in Egypt, he moved to the United States for further studies, which resulted in a successful career in engineering.

\section{The Role of Self-efficacy}

Participants in this study admitted that their parents had always assured them that they were capable of achieving any goal that they committed to. Furthermore, while planting dreams of wonderful lives their offspring would have if they practiced certain professions, parents admitted their children in reputable schools, provided them with tutors, and monitored their progress to ensure extensive learning and high grades. Good education and high academic achievement, along with time-management skills, determination, and commitment that the parents engrained in their children, gave them efficacy to pursue the careers that they, or their parents, selected, regardless of difficulty.

Nabil, financial executive from Egypt practicing in the U.S. confirmed that the encouraging and supportive environment that his parents provided at home had a significant impact on his confidence to pursue his career, 
As far as I can remember, my mother always said that I will grow up to manage the finances of a large corporation, and that my brother would become a mechanical engineer. My parents affirmed our interests repeatedly and expressed their pride in our interests. They often entrusted me with the family's budget, and gave me full freedom to allocate payments for various bills and obligations, and praised me profusely when I was able to save money at the end of most months. They generously bought my brother cars and airplanes, knowing full well that he dismantled every toy to extract its engine and attempt to create a new machine. I often questioned my parents' sensibility for continuing to give him new expensive toys, realizing that he would take them apart.

Nabil is now a chief financial officer at a large organization, while his brother is a highly creative mechanical aeronautical engineer. He believes that his parents' confidence in his and his brother's abilities, even at a very young age, along with the opportunities that they offered them to develop their interests and practice them, and the sacrifices that the brothers observed their parents make to give the best education possible, gave them confidence in their abilities to achieve their academic and career aspirations, and were powerful motivators for them to exert the necessary efforts to achieve their goals despite the many challenges they experienced along the way.

It seems evident in this study that collectivist societies, in which families are involved and invested in their children's scholastic and social accomplishments, and applaud and highlight their capabilities, help children develop self-efficacy which, according to Bandura's (1986, 1989b, 1991a) social cognitive theory, prompts the self-regulated learner to set challenging goals for him- or herself, develop strategies, and implement them to achieve these goals. The individual with a high sense of efficacy is motivated to achieve the challenging goals with confidence in his knowledge and abilities (Zimmerman, 1989, 1990b).

This study also seems to confirm that positive verbal messages that a child hears are a powerful source of motivation and self-efficacy, while negative messages that a child receives can be destructive (Pajares, 2005). The study also highlighted the self-fulfilling prophecy theory that maintains that parents' predictions or expectations motivate their children to set high goals for themselves, and exert the necessary effort to achieve success (Haller and Portes, 1973; Reitzes and Mutran1980; Rosenthal1974). At the same time, parental expectations stimulate their children's persistence and motivates success in school (Davis-Kean2005; Pearce2006; Vartanianet al.2007). Furthermore, high parental expectations inspire students to advance academically and aim to earn higher grades and enroll in college, and enabls students to flourish socially and become more adaptable to change (Hossler and Stage, 1992; Peng and Wright, 1994; Reynolds, 1998).

Understanding the culture and mindset of a collectivist language learner is essential to establishing a relationship of trust and respect between teacher and student. This relationship can be a catalyst for motivating the learner to accept the target culture 
and learn its language while interacting with fellow learners and other people as a means to learning through the sociocultural model. This close bond, which is necessary to collectivist students who are separated from their close support system, also paves the road for the teacher to gradually give students autonomy in their own learning process, a concept that is new to most students from collectivist cultures. Their educational experiences, in most instances, observed traditional classroom practices in which the teacher lectured and wrote on the board, while students listened, took notes, and memorized to prepare for being drilled on the material later (Kaur \& Noman, 2015). However, mediation, a fundamental element in Vygotsky's sociocultural theory, emphasizes the role of influential people who direct the learner toward the most suitable and effective learning experiences. Vygotsky (1978 cited Wertsch, 1985) believed that learning takes place when two or more people, with varying levels of skill, interact, thus enabling the learner to acquire and enhance knowledge.

\section{Empowering Collectivist Language Learners}

Individuals in collectivist societies generally believe in the power of the group (Hofstede 1980, 2001), and identify themselves as members of the group in all aspects of their lives, including their education and career goals. At the same time, self-efficacy, which they gained through their desire to honor their families by working hard and earning excellent grades, affirmed them of their capabilities to learn a new language, even while they are away from their home cultures and the teaching styles to which they are accustomed. Based on this understanding, the following recommendations are made to empower collectivist language learners and help them meet their language proficiency goals.

\section{Develop working groups}

Vygotsky perceives language as a social phenomenon that cannot flourish in isolation. Instead, interaction nurtures the learner's personality and cultivates it to evolve within a community. Since language is socially based, meaningful and relevant social interaction should always go hand in hand with language learning, particularly for learners of languages other than their native one. (Sanchez, 2004). The sociocultural theory, endorsed by Vygotsky's Zone of Proximal Development, proposes that learning a second language should be a "collaborative achievement that is mediated by sociocultural factors" (Lantolf, 2000). Furthermore, Ellis (2000) reiterates that learning is generated through and in interaction with others. He proposes that social interaction mediates learning as learners first perform a new task with another person, which allows the learner to "internalize" the task, subsequently can perform the task independently. In addition, working in groups is more conducive to learning for students from collectivistic societies. Being members of a group, these students' productivity is maximized when they feel that the success or failure of the project is 
shared; therefore, they must produce the best results for the group. Chinese students, for example, are raised with an achievement orientation that is based on collectivism and interdependence. Topping the list of core collectivist values is loyalty to family and community members. In the Chinese culture, for example, this value is known as filial piety, a Confucian virtue emphasizing the importance of family allegiance and duty of care for parents and elderly family members (Brislin, 1993). Filial piety is highly motivating to collectivist learners because success or failure impact their group or entire extended family, to whom they feel obligated to exert their optimum effort toward success.

It is worthy to mention, however, that in collaborative groups, a leader, who assumes the role of an expert, usually emerges to help the learners who resemble the novices (Donato, 1994). This practice simulates the scaffolded expert-notice cooperation of peers and produces similar learning results (Aimin, 2013). Furthermore, Shayer (2002) proposed that the consolidated knowledge that is generated from collaboration among $L 2$ peers creates a ZPD reservoir of information that they can all benefit from.

Teachers must not undermine the impact of anxiety and embarrassment on learners who avoid taking a risk and speaking up in a language that they're not proficient in for fear of looking foolish. Creating small working student groups inside or outside of class minimize learners' discomfort and trepidation, and allow social interaction to play its role in language learning.

\section{Provide L2 students opportunities to communicate their personal voice}

Educators must recognize that some of their students come from educational systems that are based on rote memorization and recitation of data; therefore, they lack the skills to develop creative learning strategies. Simister (2004) emphasizes the importance of guiding students into becoming creative learners who apply learning in their daily activities and develop learning strategies, which will motivate them to expend more effort toward learning the language. Focusing on language structure, on the other hand, does not contribute to the development of their intellectual abilities, resulting in demotivating learners. In fact, some educators recommend adding literature to the curriculum in order to elevate the learners' vocabulary and refine their critical thinking abilities (Turuk, 2008). Moreover, William and Burden (1997) caution language instructors that sociocultural theory advocates that teaching should not be concerned "just with theories of instruction, but with learning to learn, developing skills and strategies to continue to learn, with making learning experiences meaningful and relevant to the individual, with developing growing as a whole person." Their whole person approach to learning places responsibility on the learner to learn to make meaning of the new material. Consequently, using every-day issues and experiences as lesson topics for $L 2$ students provides them with opportunities to contribute and makes the learning relevant. 


\section{Practice cultural responsiveness}

Language instructors should exhibit cultural responsiveness by understanding the cultures that are represented in their classroom and the educational and learning approaches of those cultures. It is also imperative that teachers realize that students represent a variety of cultures, traditions, racial and ethnic backgrounds, religious and political beliefs, relational patterns, as well as family and societal values; thus, they have unique styles by which they learn, communicate, and conduct themselves (Gay, 2000; Pai, Adler, \& Shadiow, 2006). Recognizing the impact of culture on learning and teaching, educators practice cultural responsiveness by celebrating the diversity in the classroom and valuing the uniqueness of each student's culture, and by utilizing cultural knowledge to enhance student learning (Ariza, 2010; Gay, 2000; Terrell \& Lindsey, 2009). Assessment, for example, is an important factor that should be considered by teachers of international students. Various collectivistic cultures place tremendous emphasis on standardized tests scores, because of the impact that those scores have on a person professionally and socially, and therefore, on the family and even the community as a whole (Edmundson, 2007). However, students from some cultures are used to the standardized tests and will approach assessment tools based on critical thinking and class discussions with trepidation. So, to ensure fairness and accurate assessment to all students, a variety of evaluation measures should be used (Edmundson, 2007).

\section{Use culture as a pedagogical tool}

Although it is often overlooked as an element in language teaching and learning, culture is a fundamental component to language. It shapes people's lives and influences their thoughts and behaviors even if they move away from it (Condon, 1973). It also provides a framework of cognitive and affective behavior, and impacts perceptions and attitudes (Kuo \& Lai, 2006).

In addition to influencing people's values and behaviors, culture also impacts language, making it necessary for a language learner to master the cultural context before linguistic proficiency can occur (Kuo \& Lai, 2006). Therefore, since each is dependent on the other, teaching culture simultaneously with language is critical to language fluency. Kuo \& Lai (2006) suggest the following strategies:

Provide Culturally-based Learning Materials.

Based on the ages and proficiency levels of the students, materials in the target language such as newspapers, magazines, movies, news broadcasts, restaurant menus, TV shows, and Web sites reflect the culture and mirror behaviors of its people.

Use Common Proverbs as Transferred Tool.

Proverbs in the target language are an excellent mirror of any culture, especially if the source and history of each proverb was available. Through discussions, students will 
be intrigued to discover some similarities between the proverbs in the target language and their own cultures, or might realize that the proverbs are different to reflect the difference between the two cultures. Students will try to determine cultural values underscored in proverbs of the target culture and their own. As the similarities and differences between the cultures are being discussed, students will contribute with confidence and enthusiasm and share about their cultures that they know well and are proud of.

\section{Apply the Role Play as Sociocultural Approach.}

Role play effective and practical a sociocultural approach because it introduces students to intercultural communication. Sociocultural strategies are among the most instrumental in helping learners understand the culture, and therefore, the language (Savignon, 1997). Tomalin and Stempleski (1993) suggest that role play activities can help learners analyze cultural behavior and communication styles. Kuo and Lai (2006) propose a role play scenario in which students can share situations that created confusion because of cross-cultural misinterpretation. This exercise will teach them communication strategies in the target language.

\section{View Students as Cultural Resources.}

Teachers should take advantage of wealth of knowledge that the culturally diverse classroom provides. Teachers can ask their students to share features of their own cultures as experts. Not only will students benefit from organizing the information and communicating it to their peers, but they will learn from the diversity of cultures in their class and will gain more knowledge from connecting them to the target language culture.

It is worthy to point out that sociocultural research suggests that L2s can be proficient writers only if they can "act effectively in new cultural settings" (Hyland, 2002). These individuals advance in the socialization process by learning the values of the target culture and its expectations (Spack, 1997). During this process, a proficient L2 undergoes personal development and changes in self-image and identity, while adhering to the norms of the target community (Parks \& Maguire, 1999; Cumming, 2001).

\section{Utilize learner-centered instruction}

Considering that individuals learn and retain learning differently, English language teachers motivate their students further and help them take ownership of their learning process when they focus on the students' learning process. Some of the critical factors to be aware of are how students learns and the conditions under which effective learning occurs. Students from collectivist societies can thrive if they were given the opportunity to become team members in the learning process 
by determining and sharing their learning and academic goals, and participating in developing strategies to achieve language competence. This will help "learners make sense of course material and develop a deeper understanding than they would if they passively listened to a lecture" (Huba \& Freed, 2000, p. 36). Not only that, but placing language learners at the center of the learning process allays their anxieties and gives them confidence to ask questions and share their thoughts and culturally-distinctive experiences, and the interaction with classmates enhances their social, cultural, and linguistic learning (Arkoudis, 2006; Kumaravadivelu, 2008).

\section{Scaffold students' learning}

One cannot discuss language learning without considering scaffolding, since it underscores that through socialization, "a knowledgeable participant can create by means of speech and supportive conditions in which the student can participate in and extend current skills and knowledge to a high level of competence" (Donato, 1994). Therefore, while implementing this structure, the teacher, who is viewed as the expert, models a learning task to the student, or novice, and provides only necessary guidance and assistance, gradually reducing it to allow the student to become self-regulated. A teacher's assistance is discontinued as soon as the student demonstrates the ability to function independently with the new language. To determine the appropriate level of help and the degree of graduation, the teacher must develop a custom-designed plan for the student, then constantly assess the learner's ZPD (Aljaafreh \& Lantoff, 1994).

By observing the teacher perform a strategy, an L2 student from a collectivistic culture, in which a teacher is highly revered, becomes more enthusiastic about learning, has clear understanding of the direction and purpose of the task, perceives the expectations, anticipates the result, and learns more effectively (McKenzie, 1999). Furthermore, scaffolding endorses students' language proficiency and content knowledge, along with cultural transitioning, as a result of interaction with peers and instructors which promotes cognitive development. "Social processes allow the language to become a cognitive tool for the individual" (Ohta, 2000).

While cooperation and interaction with other students comes naturally to students of collectivist backgrounds, "teachers need to monitor students in cooperative groups closely for two main reasons: first, to insure that each student is being sufficiently challenged (that is, to see that students are given tasks that lie within their zones of proximal development), and second, to determine that each student is learning the intended material" (Doolittle, 1997).

Aware of their students' cultural and linguistic limitations, L2 teachers must always clarify meaning and simplify language, explain culturally-exclusive expressions and idioms and show appropriate context at which they can be used, and speak at a pace 
that students can understand, and articulate words clearly while enunciating to help students recognize words easily and avoid confusion.

\section{Use a variety of instructional strategies to address different learning styles}

Although students from collectivist countries could benefit from different learning methodologies and styles, they may be accustomed to the styles practiced in their countries, with a common practice including listening quietly to the teacher's lecture without contributing with any opinions or questions, then memorizing information and regurgitating it on examinations. The fact remains, however, that they come with knowledge, experiences, and cultural influences that determine how they approach learning. Therefore, utilizing a variety of teaching strategies and soliciting students' feedback on the most effective ones will address all the students' needs and ensure their success.

To allow students to internalize learning, teachers should use the culture that they're in, as well as the students' home cultures as learning tools. Through interaction with the students, instructors can learn about students' prior experiences and cultural values, then incorporate them in teaching (Arkoudis, 2006).

Some effective strategies that Lin \& Scherz (2014) recommend include:

- Accommodate collectivistic learners by creating small collaborative groups that require students to work interdependently to accomplish a common goal or complete an activity.

- Empower students to scaffold each other by executing reciprocal learning in which they take turns teaching their peers as "experts" in their small groups, and practice allowing their "novices" gradually become self-regulated.

- Facilitate small group discussions, choosing course topics that allow students to share their ideas and compare perspectives and points of view and discover commonalities and differences among group members.

\section{Provide clear directions and course expectations}

It is safe to assume that no one enjoys being embarrassed or shamed. But to people from some collectivistic cultures, failure to meet their teacher's or parents' expectations can be particularly humiliating and distressing, especially if it was a result of lack of information or misunderstanding instructions. To help students avoid unintentional awkward situations, instructors need to provide clear and detailed instructions that all students can comprehend. Teachers cannot assume that students have the needed background to understand directions, and should not use any slang or culturallyspecific vocabulary. 
The course syllabus needs to be as specific as possible, stating in detail the instructor's expectation and the consequences for failing to meet them. Particulars of the course should include the design of the course, expected outcomes, required textbook, clear instructions about assignment and their due dates, penalties for late submissions, dates for quizzes and exams, rubric to clarify how grades are allocated. Since asking questions is viewed by some collectivistic cultures as disrespectful to the teacher, having the necessary information clearly stated in the syllabus will prevent confusion and give students a higher chance for success.

While some values are vital to some cultures, the same ones might be relaxed in others. For example, punctuality is expected and is viewed as a demonstration of respect in some cultures, being on time is not as critical in others. Personal space is extremely guarded by some social groups, while close physical contact is a sign of approval and affirmation in others. Therefore, instructors should seize every opportunity to point out some of the cultural differences and educate their students on cultural values and social and professional expectations such as respecting people's time and space. This information can be in the context of communicating to students the importance of making appointments with the instructor to discuss their expectations from the course, how to ask for help with studying for exams, best approaches for preparing for exams, and other helpful measures in their cultural adjustment pursuits.

Most importantly, culturally-responsive instructors who are empathetic to the collectivistic students and understand their closeness to their families, seek to fill the void resulting from being away from their family units by creating a community of fellow students and teachers in which they feel safe and trust its members. By being available, attentive, friendly, and helpful outside the classroom setting, teachers can earn the students' trust and help them adapt to their new environment so they can thrive academically (Lin \& Scherz, 2014).

\section{Be aware that collectivists approach decision-making differently}

As discussed earlier, unlike individualists, collectivist parents teach their children the value of cooperation and collectivism from their infancy through stories and nursery rhymes. Children are also taught to view the family as a whole of which they are a part. The parents, in turn, perceive their children as an extension of themselves; thus, they are responsible for their actions while the offspring feel that their achievements reflect the worth of their family not just themselves (Kim \& Hong, 2007). As a result, the children are taught to value and strive for academic excellence to honor their families (Bhattacharya \& Schoppelrey, 2004; Chao, 1995; Chen \& Lan, 1998; Pettengill \& Rohner, 1985; Markus \& Kitayama, 1991; Triandis, 1995). With the family unit and its honor and the unit of close friends at the forefront for collectivistic students, they value the opinions and approval of these significant people, who therefore, influence the students' decision-making process 
and their goal selection. In many cases, the premise of collectivists' decisions, which is arrived at in collaboration with one or more members of the unit, is for the benefit of or to solve a particular problem impacting the unit or group. Inspired by respect for family, especially older members, or group of friends, this value causes collectivist students to conform and avoid making decisions even related to minor choices when they are away from their unit (Ohbuchi et al., 1999).

Within the same context, students from collectivist cultures avoid challenging or critiquing another person's ideas and are sensitive to social consequences if they are mistakenly perceived as harsh or offensive (Güss, Strohschneider, \& Halcour, 2000). Moreover, studies suggest that collectivist emphasis on group values over the individual results in a cognitive focus on the group ( $\mathrm{Ji}$, Pen, \& Nisbett, 2000). Because collectivists view their world as a whole of which they are a part, they do not rush to voice their opinions until they have sufficient information on various potential outcomes. Their infrequent voicing of their opinions, in contrast with individualists, leads educators to conclude that students from collectivistic cultures cannot think critically.

Accepting D'Angelo's (1971) definition of critical thinking being a "process of evaluating statements, arguments, and experiences," a collectivist student from Saudi Arabia, for example, was unable to adhere to instructions of his composition class teacher who asked the class to write and argumentative essay on an issue that the instructor presented to the class. The student viewed being argumentative as an expression of defiance and disrespect, and proceeded to write a descriptive essay on the same issue. When the instructor realized the motive behind the student's decision to disregard the assignment requirements, he assured the student that questioning the validity of evidence or having a different perspective is not regarded as disrespectful, and presented the concept of argumentative writing as inquiry and evaluation of an idea where the individual becomes consciously aware of his thinking process. Reluctantly, the student was more willing to write argumentatively.

\section{Empowering with self-efficacy}

With this study substantiating the significant impact of self-efficacy on collectivist students' motivation to learn, it is imperative to understand the thinking of students with high self-efficacy and how instructors can capitalize on it to maximize learning, while coaching students with low self-efficacy and providing them with the tools to believe in their abilities to learn a new language. In addition to influencing a person's perception of ability, self-efficacy also plays a significant role in regulating a person's cognitive, affective, and behavioral motivation, and higher achievement in difficult tasks results in higher self-efficacy (Bandura, 1993). 
Bandura (1986) posits that "unless people believe that they can produce desired effects and forestall desired ones by their actions, they have little incentive to act. Whatever other factors may operate as motivators, they are rooted in the core belief that one has the power to produce the desired results." Bandura (1995) goes further to suggests that, "People's level of motivation, affective states, and actions are based more on what they believe than on what is objectively the case." Therefore, to remedy students' low self-efficacy, instructors need to give them tasks that are more challenging than they perceive themselves capable of accomplishing. When they achieve these tasks, their self-efficacy is enhanced and they are motivated to be confronted by even more challenging tasks.

\section{Conclusion}

This study corroborated Bandura's theory that, "most human behavior is learned observationally through modeling: from observing others one forms an idea of how new behaviors are performed, and on later occasions this coded information serves as a guide for action" (1977a). These views led him to advocate social modeling as a step toward self-efficacy, where a person is motivated by a role model who exhibits selfefficacy acquired by overcoming adversities and achieving goals.

Since Bandura submitted the model of self-efficacy as a critical component to learning, he also defined it as the belief in one's ability to influence life's events and control the way he or she experiences them (1994). While self-efficacy can impact all facets of a person's life, it is not a trait that one is born with; yet, according to Bandura, anyone has the ability to develop and enhance his or her self-efficacy. To develop self-efficacy, he theorized that a person needs to have mastery experiences by reaching challenging goals through exerting dedicated efforts. Once these goals are reached, the person needs to acknowledge the satisfaction gained by achievement.

On the whole, Bandura perceived human behavior as ongoing interactions of the cognitive, behavioral, and environmental influences. Therefore, self-efficacy is critical to the intellectual and psychosocial development of an individual. Not only does it impact academic performance, but it also influences choices, interpersonal relationships, and wellbeing. Consequently, students from collectivist cultures with a strong sense of self-efficacy are better able to confront the rigors of learning a new language in an individualist society (Yong, 2010).

In general, individuals growing up in collectivist societies strive to honor their parents and make them proud. Accordingly, they feel a sense of duty to excel academically and pursue careers that are esteemed by the society or careers that the parents or role models practice or endorse. Bandura (1977) viewed self-efficacy expectation-an individual's confidence in his or her own ability to successfully accomplish a task- 
as a mediator of behavior or behavior change. Furthermore, self-efficacy expectation engenders persistence and endurance when faced with unexpected complications or hardships. Participants in this study corroborated Bandura's assertion that selfefficacy expectation is learned or modified through four types of information: 1) performance accomplishment: they gained confidence in their abilities when they were given opportunities to perform challenging tasks and earn success; 2 ) vicarious learning: they observed parents or other role models perform those tasks and learned from them; 3) emotional arousal: they were gratified and inspired further when they accomplished certain goals, and when they received praise and sensed parental pride; and 4) verbal persuasion: they received encouragement from significant people in their lives and gained a genuine sense of accomplishment.

Collectivist cultural values generally empower individuals with self-efficacy that enables them to adapt to new cultures, and allows them to maintain their confidence in accomplishing challenging tasks successfully. However, this theory does not apply to all international students; therefore, educators must endeavor to enrich students with high self-efficacy, and help develop confidence among students with low selfefficacy. Scaffolding is an effective approach to follow, where the teacher can provide assistance as needed, and reduce the help gradually to give a student with low selfefficacy more responsibility throughout the process.

Once learned and implemented, self-regulation-which includes time-management, organization, and study skills-will give the student a sense of control and eventually lead to autonomy. On the other hand, persistence, a common quality among students with high self-efficacy, can be utilized to challenge them beyond their comfort zone with new and more challenging tasks.

Self-efficacy is developed and enhanced as students set goals for themselves and progress through them. Therefore, educators need to help students set specific attainable and measurable goals, and encourage them to commit to achieving them to foster self-efficacy (Schwartz, 2008). At the same time, setting attainable goals at an appropriate level of difficulty for students with low self-efficacy will give them a higher probability of achieving them, and will motivate them to extend themselves to more challenging ones.

Finally, constructive feedback that students can understand and internalize will motivate them to develop effective strategies and implement them. Success derived from this process will also result in self-efficacy (Heslin \& Klehe, 2006; Schunk, 1991) as strategies lead to self-regulated learning (Schunk, 1986), and will help students stay focused on the task at hand, prioritize, and organize the facets of its process (Weinstein \& Mayer, 1986). Efforts made by instructors to develop and enhance self-efficacy will help students from collectivist societies have meaningful experiences as they develop academically and socially. 


\section{Bibliography}

1. Aimin, L. (2013). "The Study of Second Language Acquisition under SocioCultural Theory." American Journal of Educational Research, vol. 1, no. 5, 12 May 2013, pp. 162-167., doi:10.12691/education-1-5-3.

2. Aljaafreh, A., \& Lantolf, J. P. (1994). Negative feedback as regulation and second language learning in the zone of proximal development. The Modern Language Journal, 78, 465-483.

3. Arkoudis, K. (2006). Teaching international students: Strategies to enhance learning. Unpublished manuscript, Centre for the Study of Higher Education, University of Melbourne, Melbourne, Australia.

4. Bandura, A. (Ed.) (1995). Self-efficacy in changing societies. New York: Cambridge University Press.

5. Bandura, A. (1994). Self-efficacy. In V. S. Ramachaudran (Ed.), Encyclopedia of human behavior (Vol. 4, pp. 71-81). New York, NY: Academic Press. (Reprinted in H. Friedman (Ed.), Encyclopedia of mental health. San Diego, CA: Academic Press, 1998).

6. Bandura, A. (1993). Perceived Self-Efficacy in Cognitive Development and Functioning, 28 Educational Psychologist, 117, 118 (1993).

7. Bandura, A. (1986). Social foundations of thought and action: A social cognitive theory. Englewood Cliffs, NJ: Prentice Hall.

8. Bandura, A. (1982). Self-efficacy mechanism in human agency. American Psychologist, 37, 122-147.

9. Bandura, A. (1977). Self-efficacy: Toward a unifying theory of behavioral change. Psychological Review, 84, 191-215.

10. Bandura, A. (1977a). Social learning theory. New York, NY: General Learning Press.

11. Bandura, A. \& Schunk, D.H. (1981). Cultivating Competence, Self-efficacy, and Intrinsic Interest through Proximal Self-motivation. Journal of Personal and Social Psychology, 41, 586-598.

12. Brislin, R. (1993). Understanding Culture's Influence on Behavior. Orlando, FL: Harcourt Brace.

13. Cheng, X. T. (2000). Asian student's reticence revisited. System, 28, 435-446.

14. Chomsky, Noam (1968). Language and mind. Harcourt Brace \& World, New York.

15. Cook, Vivian. (2008). Second Language Learning and Language Teaching 4th Ed. London, England: Hodder Education Publishing.

16. Crose, B. (2011). Internationalization of the Higher Education Classroom: Strategies to Facilitate Intercultural Learning and Academic Success. 
International Journal of Teaching and Learning in Higher Education, 23(3), 388395. https://files.eric.ed.gov/fulltext/EJ946165.pdf

17. Donato, R., 1994. Collective scaffolding in second language learning. In: Lantolf, J. P., ed. Vygotskian approaches to second language research. London: Ablex Publishing, 33-56.

18. Doolittle, P. E. (1995). Understanding cooperative learning through Vygotsky's zone of proximal development. Paper presented at the Lilly National Conference on excellence in College Teaching, Columbia, South Carolina.

19. Doolittle, P. E. (1997). Vygotsky's zone of proximal development as a theoretical foundation for cooperative learning. Excellence in College Teaching, 8(1), 83103. Hall, A. (2007). Vygotsky goes online: Learning design from a socio-cultural perspective. Retrieved February 14, 208, from http://ro.uow.edu.au/Ilrg

20. Dweck, C. S. (2006). Mindset: The new psychology of success: How we can learn to fulfill our potential. New York: Ballantine Books.

21. Ellis, R., 2000. Task-based research and language pedagogy. Language Teaching Research, 4(3), 193-220.

22. Gay, G. (2000). Culturally responsive teaching: Theory, research, and practice. New York: Teachers College Press.

23. Guess, C. (2004). Decision Making in Individualistic and Collectivistic Cultures. Online Readings in Psychology and Culture, Unit 4. Retrieved from http:// scholarworks.gvsu.edu/orpc/vol4/iss1/3

24. Heslin, P.A., \& Klehe, U.C. (2006). Self-efficacy. In S. G. Rogelberg (Ed.), Encyclopedia of Industrial/Organizational Psychology (Vol. 2, pp. 705-708). Thousand Oaks: Sage.

25. Hird, B. (1999) English for Academic Purposes: Cultural impediments to Academic Objectivity. Prospect. Vol. 14, No.1, 28-43.

26. Hofstede, G. 1980.Culture's consequences: International differences in workrelated values. Beverley Hills, CA: Sage.

27. Hofstede, G. (2001). Culture's consequences: Comparing values, behaviors, institutions, and organizations across nations (2nd ed.). London, England: Sage.

28. Kaur, A., \& Noman, M. (2015). Exploring Classroom Practices in Collectivist Cultures through the Lens of Hofstede's Model. The Qualitative Report, 20 (11), 1794-1811. Retrieved from https://nsuworks.nova.edu/tqr/vol20/iss11/7

29. Krashen, S., and T. Terrell. (1983). The Natural Approach: Language Acquisition in the Classroom. Oxford: Pergamon.

30. Kuo, M., \& Lai, C. (2006). Linguistics across Cultures: The Impact of Culture on Second Language Learning. Journal of Foreign Language Instruction, 1-9. https://files.eric.ed.gov/fulltext/ED496079.pdf 
31. Lantolf, J. (2000). Introducing sociocultural theory. In: Lantolf, J. P., ed. Sociocultural theory and second language learning. Oxford University Press, 1-26

32. Lantolf, J, \& S Thorne. (2006). Sociocultural Theory and the Genesis of Second Language Development. Oxford University Press.

33. Lin, S., \& Day Scherz, S. (2014). Challenges Facing Asian International Graduate Students in the US: Pedagogical Considerations in Higher Education. Journal of International Students, 4(1), 33. http://jistudents.org/

34. Littlewood, W. (2001). Students' attitudes to classroom English learning: A cross-cultural study. Language Teaching Research, 5(1), 3-28.

35. Lu, M. (1998). Language learning in social and cultural contexts. Eric Digest. Retrieved October 11, 2006 from http://www.ed.gov.databases/ERIC_Digests/ ed423531.html

36. Maddux, J. E. 1995. Self-efficacy, adaptation, and adjustment: Theory, research, and application. New York: Plenum

37. McKenzie, J., 1999. Scaffolding for Success. 9(4). Available from: http://www. icelp.org/asp/Aspects of Mediation Learning Experience.htm [accessed 19 March 2020].

38. Mustafai, J. (2015). Dictionary Use as Word Solving Strategy (WSS). Academicus International Scientific Journal, 6(12), 190-198.

39. Nelson, Gayle. (2000). Individualism-Collectivism and Power Distance: Applications for the English as a Second Language Classroom. The CATESOL Journal, 12.1, 73-91.

40. Pai, Y., Adler, S. A., \& Shadiow, L. K. (2006). Cultural foundations of education. (4th Ed.) Upper Saddle River, NJ: Pearson Prentice Hall.

41. Rao, Z. (2006). Understanding Chinese Students' Use of Language Learning Strategies from Cultural and Educational Perspectives. Journal of Multilingual and Multicultural Development, 27(6), 491-508. https://doi.org/10.2167/ jmmd449.1

42. Sanchez, A. (2004). The Task-based Approach in Language Teaching. Theory and Practice in Language Studies, 4(1), 39-71. https://um.es/engphil/ijes

43. Schunk D.H. (1995) Self-Efficacy and Education and Instruction. In: Maddux J.E. (eds) Self-Efficacy, Adaptation, and Adjustment. The Plenum Series in Social/ Clinical Psychology. Springer, Boston, MA. https://doi.org/10.1007/978-14419-6868-5_10

44. Schunk, D. H. (1991). Self-efficacy and academic motivation. Educational Psychologist, 26, 207-231. 
45. Schwartz, M. H., "Expert learning for law students" (2008). McGeorge School of Law Scholarly Books. 23. https://scholarlycommons.pacific.edu/ facultybooks $/ 23$

46. Seedhouse, P., 1999. Task-based Interaction. ELT Journal, 53(3), 149-156

47. Shayer, M., (2002). Not just Piaget, not just Vygotsky, and certainly not Vygotsky as an alternative to Piaget. In: Shayer, M., ed. Learning intelligence, cognitive acceleration across the curriculum from 5 to 15 years. UK: Open University Press

48. Sihna, J.B.P. (2014). Collectivism and individualism. Psycho-Social Analysis of the Indian Mindset, XXI, 27-51.

49. Simister, J., 2004.To think or not to think: a preliminary investigation into the effects of teaching thinking. Improving Schools, Sage Publications, 7 (3), 243254

50. Skinner, B.F. (1957). Verbal Behavior. Acton, MA: Copley Publishing Group.

51. Sleeter, C. (2001). Preparing teachers for culturally diverse schools: Research and the overwhelming presence of whiteness. Journal of Teacher Education, 52, 94-106.

52. Terrell, T.D. 1982. The natural approach to language teaching: An update. Modern Language Journal 66: 121-132.

53. Turuk, M. C. (2008). The Relevance and Implications of Vygotsky's Sociocultural Theory on the Second Language Classroom. ARECLS, 5, 244-262.

54. Vygotsky, L.S. (1987). The collected works of L. S. Vygotsky: Volume 1. Thinking and speaking. New York, NY: Plenum Press.

55. Vygotsky, L.S. (1978). Mind in society: The development of higher mental processes. Cambridge, MA: Harvard University Press.

56. Weinstein, C. E. \& Mayer, R. E. (1986). The teaching of learning strategies. In M. C. Wittrock (Ed.), Handbook of research on teaching (pp. 315-327). New York: Macmillan Publishing Company.

57. Wertsch, J., 1985. Vygotsky and the social formation of mind. UK: Harvard University Press

58. Williams, M. and Burden, R., 1997. Psychology for language teachers, a social constructivist approach. UK: Cambridge University Press

59. Xiao, L. X. (2005). Do we reliably know what EFL students like in English classrooms at university level? The Journal of Asia TEFL, 2(3), 67-94.

60. Yong, Fung Lan. (2010). A Study on the Self-Efficacy and Expectancy for Success of Pre-University Students European Journal of Social Sciences - Volume 13, Number 4. 